\title{
Dewaterability of sludge conditioned with surfactant DDBAC pretreatment by acid/alkali
}

\author{
Chen Hong • Yi Xing • Xiufu Hua • Yanxiao Si • \\ Geng Qiao $\cdot$ Zhiqiang Wang
}

Received: 17 January 2015 /Revised: 28 January 2015 / Accepted: 29 January 2015 /Published online: 7 March 2015

(C) Springer-Verlag Berlin Heidelberg 2015

\begin{abstract}
The potential benefits of surfactant-conditioned sludge dewatering treatment with acid/alkali pretreatment were investigated in this study. The water content of dewatered sludge $\left(W_{\mathrm{C}}\right)$ and specific resistance of filtration (SRF) were used to evaluate sludge dewaterability. Extracellular polymeric substance (EPS) content, bound water content, zeta potential, and rheological properties were measured to explain the change of dewaterability observed in the conditioning process. By introducing dodecyl dimethyl benzyl ammonium chloride (DDBAC), the EPS content of the sludge supernatant changed, and bound water content, charge strength, and apparent viscosity decreased simultaneously. Although DDBAC-conditioned sludge in strong alkaline had low bound water content, $W_{\mathrm{C}}$ and SRF increased rapidly because of the dramatically increasing of EPS in sludge supernatant. Remarkable decrement was observed in bound water
\end{abstract}

Electronic supplementary material The online version of this article (doi:10.1007/s00253-015-6451-2) contains supplementary material, which is available to authorized users.

C. Hong $\cdot$ Y. Xing $(\bowtie) \cdot$ Y. Si $\cdot$ G. Qiao $\cdot$ Z. Wang

Department of Environmental Engineering, University of Science

and Technology Beijing, Beijing 100083, China

e-mail: xingyi@ustb.edu.cn

C. Hong

Reasearch Center for Eco-Environmental Sciences,

Chinese Academy of Science, Beijing 100085, China

X. Hua $(\bowtie)$

Department of Scientific Research and Development,

Tsinghua University, Beijing 100084, China

e-mail: hua_xiufu@163.com

G. Qiao

School of Chemical Engineering, University of Birmingham,

Edgbaston, Birmingham B15 2TT, UK content and $W_{\mathrm{C}}$ in DDBAC-conditioned sludge which was in weak acid environment for comparison. The results indicated that $75 \mathrm{mg} / \mathrm{g}$ of DDBAC at $\mathrm{pH} 4.84$ was the optimum under which $W_{\mathrm{C}}$ and SRF were at their lowest point in sludge, $58.22 \%$ and $0.521 \times 10^{13} \mathrm{~m} / \mathrm{kg}$, respectively.

Keywords Sludge $\cdot$ Surfactant $\cdot$ Acid/alkali pretreatment . Extracellular polymeric substance $\cdot$ Dewatering

\section{Introduction}

Sludge is a multiphase medium that contains water, minerals, organic substances, proteins, and microorganism cells. It is a by-product in treatment processes of wastewater, particularly municipal wastewater (Feng et al. 2009; Neyens et al. 2004; Yuan et al. 2011a, b; Zhang et al. 2010). The moisture content of sludge is generally between $99 \%$ (before thickening) and $95 \%$ (after thickening). Thus, sludge should be dewatered prior to its final disposal (Liu et al. 2013; Tokumura et al. 2007). Different kinds of polymers (i.e., polymeric ferric sulfate, polyaluminium chloride, and polyacrylamide) are widely used in conditioning sludge prior to dewatering (Ma et al. 2007; Zhao and Bache 2001). Nonetheless, the use of these polymers is limited due to the following reasons. To begin with, the water content level achieved through centrifuge or belt press dewatering ranges only from 75 to $80 \%$, which fails to satisfy the requirements of incineration or landfill disposal (Neyens and Baeyens 2003). Secondly, the polymer residual left in the dewatered sludge poses has long-term environmental risks, especially when the sludge cakes are ultimately disposed in landfills (Bolto and Gregory 2007).

These drawbacks, along with the imposition of stricter treatment and disposal regulations, have given rise to a 
demand for more efficient sludge conditioning methods. Previous studies have explored the use of surfactant as an alternative chemical conditioner for sludge (Chen and $\mathrm{Gu}$ 2004; Huang and Fu 2000; Yuan et al. 2011a, b). Chen and $\mathrm{Gu}$ (2004) reported that surfactant (dodecyl betaine) is more effective to enhance sludge dewaterability and filterability than traditional sludge conditioners $\left(\mathrm{FeCl}_{3}, \mathrm{CaO}\right)$. Yuan et al. (2011a, b) conditioned sludge by using electrolysis and surfactants and also obtained similar results. Their research studies also showed that the introducing of surfactants improves the EPS content in the sludge filtrate and thus improves the sludge dewatering performance significantly. EPS which contains plenty of bound water in sludge is composed of proteins, polysaccharides, nucleic acids, and so on ( $\mathrm{Yu}$ et al. 2008; Hua et al. 2010a, b). Many previous studies have proposed that the amount of EPS (Houghton et al. 2001; Novak et al. 2003; Rosenberger et al. 2005; Zhang et al. 2015) and bound water content (Vaxelaire and Cézac 2004) have a significant impact on sludge dewaterability. But, the mechanism of EPS and bound water on sludge dewatering performance under the condition of surfactants is not clear, and further research is necessary. Meanwhile, not only the content and properties of EPS change, but also $\mathrm{pH}$ value could influence sludge dewatering performance. Therefore, the study of sludge dewatering performance under different acid/alkali condition could serve as basis for the optimization of mud separation in the sludge dewatering process.

The effects of surfactant conditioning on sludge dewaterability with or without acid/alkali pretreatment were investigated in this study. The water content $\left(W_{\mathrm{C}}\right)$ and its specific resistance to filtration (SRF) of dewatered sludge were used to evaluate sludge dewaterability. In addition, EPS, zeta potential, rheological properties, and bound water content were measured to elucidate the mechanisms of sludge dewatering under the surfactant conditioning with acid/alkali pretreatment process.

\section{Materials and methods}

Test materials

The sludge used in this study was collected from Qinghe municipal wastewater treatment plant in Beijing, China. The sludge was thickened by gravity to the required solid content and stored in a plastic container at $4{ }^{\circ} \mathrm{C}$. All of the experiments were completed in $48 \mathrm{~h}$. The main characteristics of the thickened sludge are presented in Table 1.

The surfactant applied as sludge conditioner was dodecyl dimethyl benzyl ammonium chloride (DDBAC) (analytical grade, Xinyang Chemical Company, China), which is a cationic surfactant with a molecular formula of $\mathrm{C}_{21} \mathrm{H}_{38} \mathrm{NCl}$ and molecular weight of $340.00 \mathrm{~g} / \mathrm{mol}$.
Table 1 Properties of thickened sludge used in this study before condition

\begin{tabular}{llc} 
& VSS & $34,363.78 \pm 254.18 \mathrm{mg} / 1$ \\
& $\mathrm{pH}$ & $7.29 \pm 0.08$ \\
& Water content & $95.05 \pm 0.37 \%$ \\
& SRF & $(1.59 \pm 0.12) \times 10^{13}$ \\
& Bound water & $3.24 \pm 0.06 \mathrm{~g} / \mathrm{g}$ \\
& EPS & $1118.29 \pm 53.36 \mathrm{mg} / 1$ \\
$T S S$ total suspended & Protein & $877.42 \pm 38.28 \mathrm{mg} / 1$ \\
solids, $V S S$ volatile & Polysaccharide & $146.76 \pm 8.23 \mathrm{mg} / 1$ \\
suspended solids & Nucleic acid & $94.11 \pm 6.85 \mathrm{mg} / 1$ \\
\hline
\end{tabular}

All the other chemicals used were of analytical grade, except for bovine serum albumin and calf thymus DNA, which were biochemical grade. All the solutions were freshly prepared using deionized water before experimentation. Sulfuric acid $\left(\mathrm{H}_{2} \mathrm{SO}_{4}, 4 \mathrm{M}\right)$ and sodium hydroxide $(\mathrm{NaOH}, 4 \mathrm{M})$ were used to pretreat sludge.

\section{Sludge condition with surfactant alone}

The sludge sample was placed in a beaker with DDBAC. The resulting mixture was stirred for $20 \mathrm{~min}$ at a speed of $100 \mathrm{rpm}$. Approximately $50 \mathrm{ml}$ of sludge was filtered and dewatered in a 150-mm Buchner funnel with a quantitative filter paper at a vacuum tightness of $0.055 \mathrm{MPa}$.

Sludge condition with surfactant in different $\mathrm{pH}$ values

The concentrated sludge was in a beaker and had its $\mathrm{pH}$ controlled by adding $4 \mathrm{M}$ sulfuric acid or $4 \mathrm{M}$ sodium hydroxide. DDBAC was then added. The resulting mixture was stirred for $20 \mathrm{~min}$ at a speed of $100 \mathrm{rpm}$. Approximately $50 \mathrm{ml}$ of sludge was filtered and dewatered in a 150-mm Buchner funnel with a quantitative filter paper under a vacuum tightness of $0.055 \mathrm{MPa}$.

Analytical methods

Sludge dewaterability was evaluated in terms of the water content of dewatered sludge $\left(W_{\mathrm{C}}\right)$ and specific resistance of filtration (SRF). The $W_{\mathrm{C}}$ was determined using the following equation:

$W_{\mathrm{C}}=\left(W_{1}-W_{2}\right) / W_{1} \times 100 \%$

where $W_{1}$ is the weight of wet filter cake and $W_{2}$ is the weight of filter cake after drying at $105^{\circ} \mathrm{C}$ to constant weight.

In the sludge conditioning process, both filtrate volume and filtration time were recorded to assess sludge SRF. SRF was calculated as the slope of a linear plot of volume vs. time/volume (Lo et al. 2001). 
Protein, polysaccharide, and nucleic acid contents of the sludge supernatant were spectrophotometrically measured using a UV/visible spectrophotometer (TU-1901, PGeneral, China). Protein content was obtained according to the method proposed by Lowry et al. (1951), in which bovine serum albumin was used as standard and absorbance was measured at $500 \mathrm{~nm}$. Polysaccharide content was assayed using the anthrone method proposed by Riesz et al. (1985), in which glucose was used as standard and absorbance was measured at $625 \mathrm{~nm}$. Nucleic acid content was measured using the diphenylamine assay proposed by Burton (1968), in which calf thymus DNA was used as standard and absorbance was measured at $595 \mathrm{~nm}$.

Bound water content was measured by differential scanning calorimetry (DSC) (404 F3 Pegasus, NETZSCH, Germany) according to the following program: The dewatered sludge samples were cooled to $-20^{\circ} \mathrm{C}$ at a rate of $10^{\circ} \mathrm{C} / \mathrm{min}$ and then warmed to room temperature at the same rate (Vaxelaire and Cézac 2004). When the sample was cooling, heat was released and an obvious exothermic peak was shown. Similarly, it showed an obvious endothermic peak in the heating stage. Bound water did not freeze under the given limited temperature of $-20{ }^{\circ} \mathrm{C}$, and the heat released by the sludge sample during the test corresponded to the heat released from free water freezing. Bound water is the difference between total water and free water in the sludge. The formula for bound water content is as follows:

$W_{\mathrm{B}}=W_{\mathrm{T}}-\Delta H / \Delta H_{0}$

where $W_{\mathrm{B}}$ is the bound water content $(\mathrm{g} / \mathrm{g}$, being the matter content in per gram dry sludge, based on dry solids, similarly hereinafter), $W_{\mathrm{T}}$ is the total water content $(\mathrm{g} / \mathrm{g}), \Delta H$ is the DSC endothermic of the sample in joules per gram, and $\Delta H_{0}$ is the standard fusion heat of ice at $334.7 \mathrm{j} / \mathrm{g}$.

Zeta potential was measured using a zeta potentiometer (ZetaPlus, BIC, USA). Because of the large resistance in original sludge, the sludge was diluted with deionized water 50 times. The zeta potential of the diluted sludge was measured for comparison with the relative value.

The rheological properties of the sludge were determined using a rheometer (MCR302, Aaton Paar, Austria). The changing rule of the apparent viscosity of the sludge was measured with increasing shear rate $(1 / \mathrm{s})$ from 1 to 100 at a constant temperature of $25^{\circ} \mathrm{C}$.

Statistical analysis

Statistical analysis was conducted using SPSS version 18.0 for Windows (SPSS, Chicago, IL). Pearson's correlation coefficient $(R)$ was used to evaluate the linear correlation between two parameters.

\section{Results}

Effect of surfactant conditioning with and without acid/alkali

The effect of DDBAC conditioning on sludge dewaterability was evaluated by measuring the $W_{\mathrm{C}}$ and SRF of the sludge. With the increasing dosage of DDBAC, sludge dewaterability was enhanced proportionally (Fig. 1a). When the dosage of DDBAC from 0 to $56.25 \mathrm{mg} / \mathrm{g}(\mathrm{mg} / \mathrm{g}$, being the DDBAC dosage in per gram dry sludge, based on dry solids, similarly hereinafter), the $W_{\mathrm{C}}$ decreased from 79.54 to $72.16 \%$. However, SRF increased from $1.592 \times 10^{13}$ to $1.743 \times 10^{13} \mathrm{~m} / \mathrm{kg}$ when the addition of DDBAC from 0 to $18.75 \mathrm{mg} / \mathrm{g}$, and then decreased to $1.22 \times 10^{13} \mathrm{~m} / \mathrm{kg}$ with the increasing DDBAC addition $(\leq 56.25 \mathrm{mg} / \mathrm{g})$. Sludge dewaterability was significantly improved when DDBAC dosage was increased from 56.25 to $75 \mathrm{mg} / \mathrm{g}$. $W_{\mathrm{C}}$ and SRF values of the sludge samples rapidly decreased from 72.16 to $64.79 \%$ and from $1.22 \times 10^{13}$ to $0.515 \times 10^{13} \mathrm{~m} / \mathrm{kg}$, respectively. That is, the $W_{\mathrm{C}}$ and SRF of the conditioned sludge declined by 7.37 and $57.79 \%$, respectively. With a further increase in DDBAC dosage, the decreasing trend of $W_{\mathrm{C}}$ and SRF slowed down. Therefore, $75 \mathrm{mg} / \mathrm{g}$ of DDBAC was determined as the optimal dosage.

These findings indicated that during DDBAC conditioning process, the acid/alkali pretreatment significantly affected sludge dewaterability in terms of $W_{\mathrm{C}}$ and SRF (Fig. 1b). Better sludge dewatering result was achieved when the sludge was conditioned by DDBAC with acidic pretreatment. The $W_{\mathrm{C}}$ of the dewatered sludge reached its minimum $(58.12 \%)$ at $\mathrm{pH}=4.84$. SRF slightly increased with a decrement in $\mathrm{pH}$ value under acidic conditions. Meanwhile, under weak alkaline conditions ( $\mathrm{pH}=8.87)$, compared with the sludge without acid/alkali pretreatment, $W_{\mathrm{C}}$ remained unchanged, while SRF slightly increased slightly. Nevertheless, sludge dewaterability weakened drastically with further increasing in $\mathrm{pH}$ value. When the $\mathrm{pH}$ value was changed from 8.87 to $12.86, W_{\mathrm{C}}$ and SRF significantly increased from 62.78 to $91.01 \%$ and from $0.628 \times 10^{13}$ to $4.666 \times 10^{13} \mathrm{~m} / \mathrm{kg}$, respectively. That is, $W_{\mathrm{C}}$ and SRF increased by 28.23 and $642.99 \%$, respectively.

Effect of EPS on the dewaterability of sludge

When a small amount of DDBAC was added $(18.75 \mathrm{mg} / \mathrm{g})$, EPS content increased from 1118.32 to $1241.66 \mathrm{mg} / 1$, probably because a greater number of EPS was dissolved rather than hydrolyzed.

When the amount of DDBAC was increased from 37.5 to $75 \mathrm{mg} / \mathrm{g}$, the EPS content in the supernatants substantially decreased from 1367.85 to $1005.93 \mathrm{mg} / 1$ (Fig. 2a). When the addition of DDBAC $>75 \mathrm{mg} / \mathrm{g}$, the downward trend in EPS content slowed, indicating that mostly EPS that could be hydrolyzed had been hydrolyzed by DDBAC. 
Fig. 1 Dewatering of sludge with surfactant conditioning pretreatment by acid and alkali. a DDBAC-conditioned sludge alone $(0-150 \mathrm{mg} / \mathrm{g})$. b DDBACconditioned sludge with acidalkali pretreatment $(\mathrm{pH}$ range 1.30 to 12.86 , DDBAC dosage $75 \mathrm{mg} / \mathrm{g}$ )

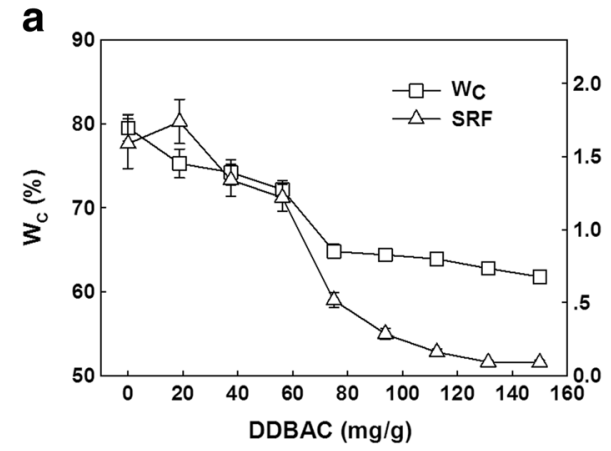

Figure 3 showed the linear regression between the EPS content and dewaterability of the sludge. Table 2 presented the Pearson correlations between EPS and $W_{\mathrm{C}} / \mathrm{SRF}$. When DDBAC was applied independently, EPS content had a highly positive correlation with $W_{\mathrm{C}}$ and $\mathrm{SRF}\left(R^{2}=0.7869, R>0.829\right.$, $P<0.01$, and $R^{2}=0.8748, R>0.935, P<0.01$, respectively). The proteins in EPS also had significantly positive correlation with $W_{\mathrm{C}}$ and SRF $\left(R^{2}=0.8319, R>0.873, P<0.01\right.$, and $R^{2}=$ $0.8974, R>0.947, P<0.01$, respectively). However, polysaccharides and nucleic acids exhibited low correlations with $W_{\mathrm{C}}$ and only a slight positive correlation with SRF. These findings are in agreement with those reported by Feng et al. (2009) and Houghton et al. (2001), who observed strong quadratic relationships between EPS and SRF.

When the sludge was jointly treated with acid and DDBAC, EPS was barely correlated with $W_{\mathrm{C}}$, for the Pearson correlation coefficient was very low (Supplementary Fig. S1). However, a positive correlation was found between EPS and SRF $\left(R^{2}=\right.$ $0.8447, R>0.915, P<0.01)$. The correlation between EPS constituents (proteins, polysaccharides, and nucleic acids) and $W_{\mathrm{C}}$ or SRF was similar to correlation between EPS and $W_{\mathrm{C}}$ or SRF, respectively. When joint treatment of alkali and DDBAC was applied, EPS had a strong positive correlation with $W_{\mathrm{C}}$ and SRF $\left(R^{2}=0.9553, R>0.977, P<0.01\right.$, and $R^{2}=0.9685, R>0.984$, $P<0.01)$. Different constituents of EPS, i.e., proteins, polysaccharides, and nucleic acids, all had significantly correlated with $W_{\mathrm{C}}$ and SRF (Supplementary Fig. S2). Protein that was the predominant component and highly correlated with $W_{\mathrm{C}}$ and
SRF would be the leading factor affecting sludge dewaterability. These findings suggested that different methods of sludge treatment have varying effects on the correlation between EPS and sludge dewaterability.

Changes in bound water in sludge cake

Figure 4a showed the proportion of constituents and bound water content in filtered sludge after DDBAC conditioning with acid/alkali pretreatment. The application of DDBAC reduced bound water in sludge. When the amount of DDBAC was increased from 0 to $75 \mathrm{mg} / \mathrm{g}, W_{\mathrm{B}}$ rapidly decreased from 3.24 to $1.58 \mathrm{~g} / \mathrm{g}$, accounting for a decrease by $51.23 \%$. When the amount of DDBAC increased, a gradual downtrend of the bound water content was observed. The trend of the changes in bound water content matched that of sludge dewaterability (Fig. 1a). Eventually, when the amount of DDBAC reached $150 \mathrm{mg} / \mathrm{g}$, the bound water content decreased to $1.31 \mathrm{~g} / \mathrm{g}$, a decrease by $59.57 \%$, compared with unconditioning sludge.

Compared with neutral conditions, the bound water content of sludge conditioning under weak acidic $(\mathrm{pH}=4.84)$ or alkaline $(\mathrm{pH}=10.01)$ conditions, as well as after DDBAC treatment, decreased remarkably (Fig. 4b). Notably, the free water content in filtered sludge increased significantly at $\mathrm{pH} \geq 10.01$ (Fig. 4b). By contrast, both $W_{\mathrm{C}}$, SRF, and bound water decreased under DDBAC conditioning with weak acidic pretreatment ( $\mathrm{pH}=4.84$; Figs. $1 \mathrm{~b}$ and $4 \mathrm{~b})$.
Fig. 2 Effect of DDBAC conditioning pretreatment by acid/alkali on EPS, protein, polysaccharide, and nucleic acid content in the sludge supernatant. a DDBAC-conditioned sludge alone (0 to $150 \mathrm{mg} / \mathrm{g})$. b DDBAC-conditioned sludge with acid-alkali pretreatment $(\mathrm{pH}$ range 1.30 to 12.86 , DDBAC dosage $75 \mathrm{mg} / \mathrm{g}$ )
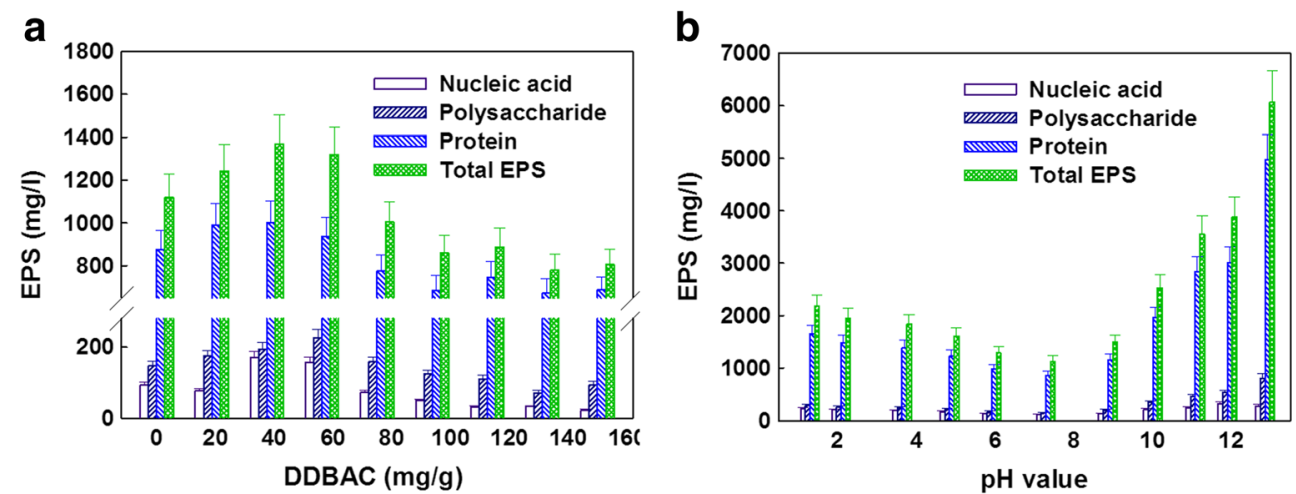


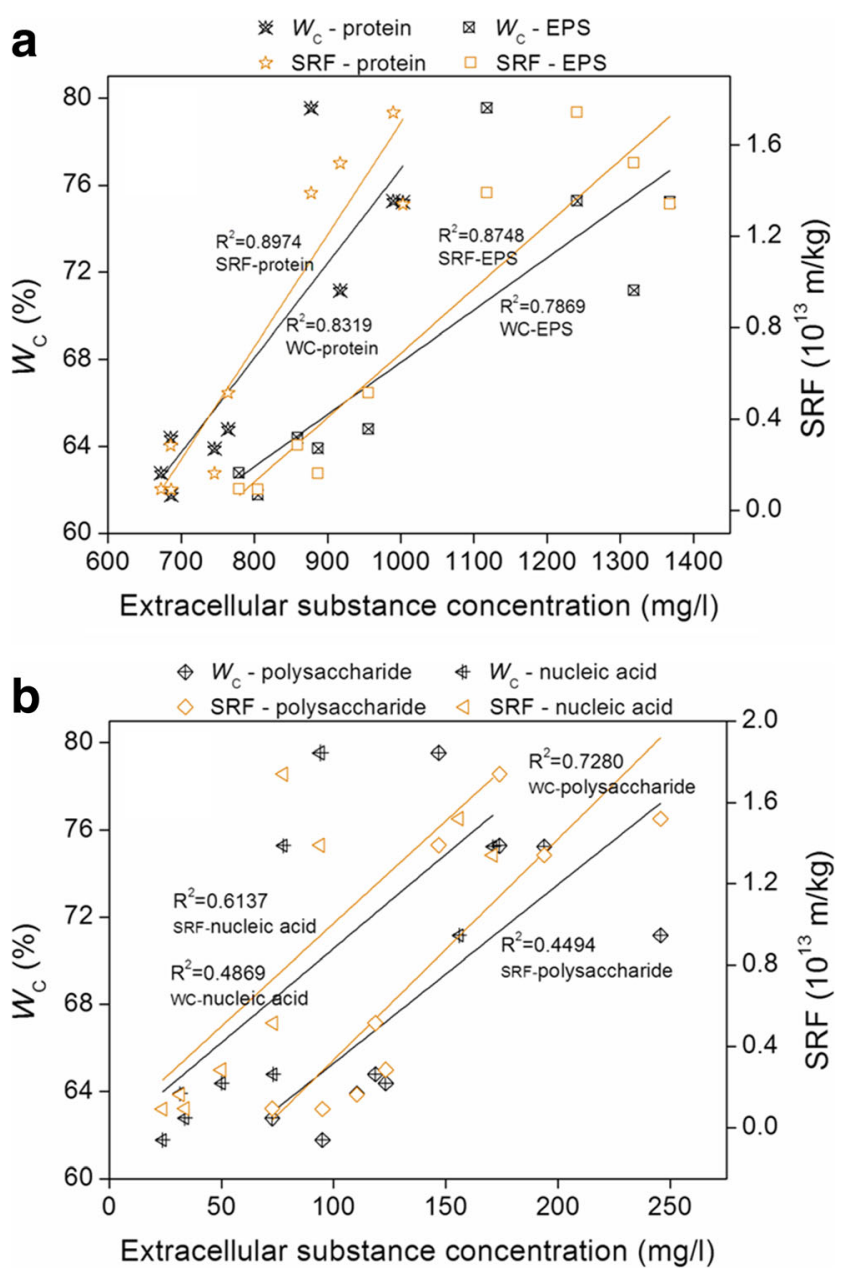

Fig. 3 Correlation between the EPS, protein, polysaccharide, nucleic acid content, and its dewaterability as measured by $W_{\mathrm{C}} / \mathrm{SRF}$ (DDBACconditioned sludge alone, and dosage: 0 to $150 \mathrm{mg} / \mathrm{g}$ ). a EPS and protein. b Polysaccharide and nucleic acid content

\section{Changes in zeta potential of sludge}

Figure 5a showed that the addition of DDBAC reduced the quantity of the electric charges of sludge. The value of zeta potential increased from -22.21 to $-15.17 \mathrm{mV}$ when the addition of DDBAC ranged from 0 to $150 \mathrm{mg} / \mathrm{g}$.

Under the combined treatment of acid and DDBAC, the value of the zeta potential increased considerably from $-19.38 \mathrm{mV}$ $(\mathrm{pH}=7.29)$ to $-2.73 \mathrm{mV}(\mathrm{pH}=1.30)$. The intensity of the electric charges decreased when the acidity was enhanced. Under the joint treatment of alkali and DDBAC, the value of the zeta potential decreased remarkably from $-19.38 \mathrm{mV}(\mathrm{pH}=7.29)$ to $-42.73 \mathrm{mV}(\mathrm{pH}=12.86)$. The intensity of the electric charges evidently increased when the alkalinity was reinforced.

\section{Changes in rheological properties}

The apparent viscosity of sludge decreased dramatically after the addition of DDBAC, and such decrease was evident when the shear rate was in a low level ( 1 to $101 / \mathrm{s})$. When the amount of DDBAC increased $(\geq 56.25 \mathrm{mg} / \mathrm{g}$ ), the downward trend in viscosity slowed (Fig. 6a). Sludge was a multiphase liquid that contains zoogloea.

As shown in Fig. 6b, under DDBAC conditioning with acid/alkali pretreatment, sludge viscosity increased when acidity/alkalinity increased. As shown in Fig. 6b, under acid/alkali pretreatment, from the higher EPS content in the supernatant and greater apparent viscosity, it could be inferred that EPS in the sludge flocs entered the sludge liquid to reinforce apparent viscosity. As a result, the EPS content in the liquid phase was so large that the addition of DDBAC $(75 \mathrm{mg} / \mathrm{g})$ failed to decrease the apparent viscosity of the sludge effectively.

\section{Discussion}

EPS is considered to be an important factor to influence sludge dewatering performance. EPS absorb on the sludge, thus making sludge difficult to compress. It aids the retention of water and significantly contributes to the water-binding capacity of the sludge floc matrix (Vaxelaire and Cézac 2004; Jin et al. 2004). The addition of surfactant and acid/alkali would affect

Table 2 Coefficients of Pearson correlation between EPS, protein, polysaccharide, nucleic acid content of the sludge, and $W_{\mathrm{C}} / \mathrm{SRF}$

\begin{tabular}{|c|c|c|c|c|c|c|c|c|}
\hline \multirow[t]{2}{*}{ Conditioning methods } & \multicolumn{4}{|l|}{$W_{\mathrm{C}}(\%)$} & \multicolumn{4}{|l|}{$\mathrm{SRF}(\mathrm{m} / \mathrm{kg})$} \\
\hline & EPS (mg/l) & Protein (mg/l) & PS (mg/l) & NA (mg/l) & EPS (mg/l) & Protein (mg/l) & PS (mg/l) & $\mathrm{NA}(\mathrm{mg} / \mathrm{l})$ \\
\hline DDBAC only ${ }^{\mathrm{a}}$ & $0.829 * *$ & $0.873^{* *}$ & $0.670^{*}$ & $0.689 *$ & $0.935^{*}$ & $0.947 * *$ & $0.853 * *$ & $0.783^{*}$ \\
\hline Acid + DDBAC ${ }^{b}$ & 0.066 & 0.072 & 0.083 & 0.054 & $0.915^{* *}$ & $0.936^{* *}$ & $0.899 *$ & $0.927 * *$ \\
\hline Alkali + DDBAC ${ }^{\mathrm{c}}$ & $0.977 * *$ & $0.974 * *$ & $0.988 * *$ & $0.927 * *$ & $0.984 * *$ & $0.986^{* *}$ & $0.984 * *$ & $0.845^{*}$ \\
\hline
\end{tabular}

$P S$ polysaccharide, $N A$ nucleic acid

${ }^{*} p<0.05$ (two-tailed); * $p<0.01$ (two-tailed)

a $n=9$

b $n=6$

${ }^{\mathrm{c}} n=6$ 

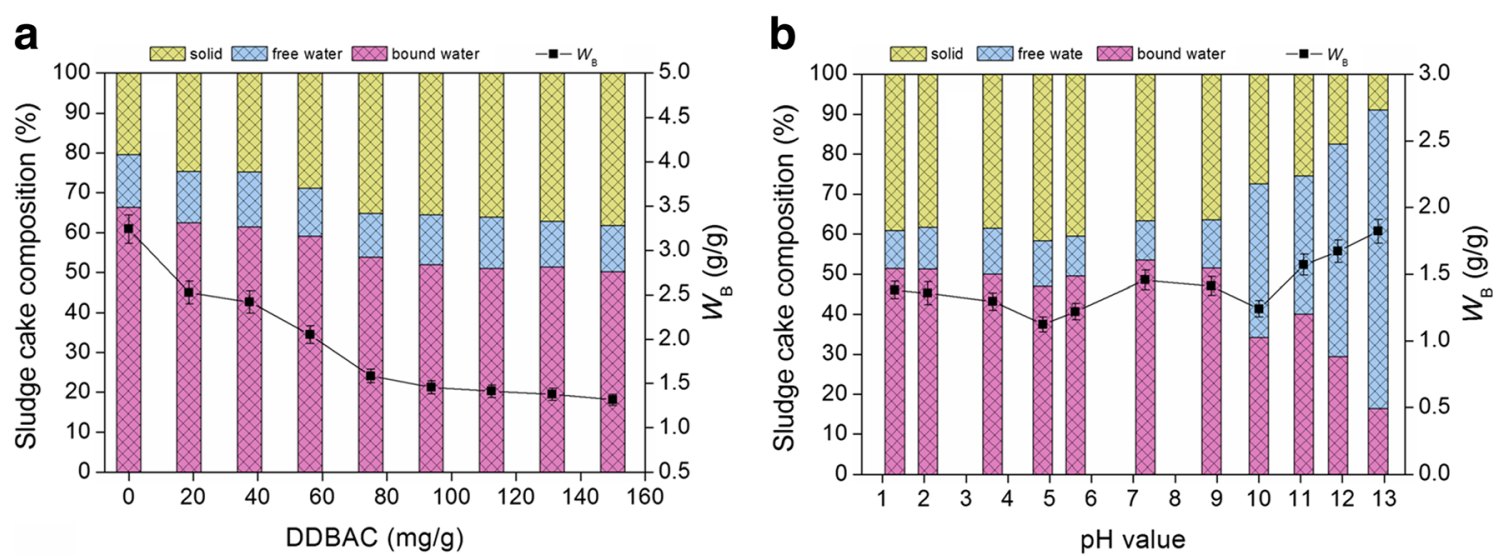

Fig. 4 Changes of composition and $W_{\mathrm{B}}$ in sludge cake. a DDBAC-conditioned sludge alone (0 to $\left.150 \mathrm{mg} / \mathrm{g}\right)$. b DDBAC-conditioned sludge with acidalkali pretreatment ( $\mathrm{pH}$ range 1.30 to 12.86 , DDBAC dosage $75 \mathrm{mg} / \mathrm{g}$ )

the EPS content and thus could enhance or deteriorate sludge dewaterability (Chen et al. 2001).

Figure 2a indicated that EPS content increased firstly and then decreased with the continuous addition of DDBAC. This trend was attributed to the dispersing, solubilization, and hydrolysis properties of surfactants. The dispersive forces of the surfactants weakened the surface tension and viscosity of the sludge, thereby improving its filterability. The solubilization properties of surfactants promoted the dissolution of nondissolvable EPS, which separated themselves from the sludge and enter the supernatants. Surfactant could also boost the macro-molecular organic matter (Jiang et al. 2007; Luo et al. 2011), such as EPS, hydrolyzed into smaller organic compounds, thereby reducing the EPS level. Thus, the water bounded in EPS could release into sludge liquid, and sludge dewatering performance improved.

The EPS content in the liquid increased, which consequently increases the viscosity of the sludge (Wang et al. 2006). This change increased SRF and deteriorated sludge filterability (Fig. 1). With DDBAC dosage increasing ( $37.5 \mathrm{mg} / \mathrm{g}$ ), EPS content continued to increase (Fig. 2a). More and more non-dissolvable EPS was stripped from the sludge flocs and dissolved in the fluid, and bound water was released. However, SRF decreased in this phase may be due to further addition of DDBAC; it could reduce the surface tension of the sludge and then improve sludge filterability. This observation suggested that most of the EPS that can be dissolved by DDBAC have been peeled off from the flocs into the fluid. After that, the dissolution quantity of EPS decreased, and meanwhile, EPS was still hydrolyzed; therefore, the total amount of EPS in the sludge liquid decreased.

With the combined effects of DDBAC and acid/alkali pretreatment, the EPS content in the sludge supernatant changed, as indicated in Fig. 2b. When sludge liquid became more acidic or alkaline, the EPS level significantly increased. This finding coincided with the finding reported by $\mathrm{Chen}$ and $\mathrm{Gu}$ (2004), who observed that EPS content increased when the surfactant-conditioned sludge was placed in a strong acidic environment. The acid/alkali pretreatment disintegrates sludge flocs, peels off the non-dissolvable EPS, and converts them into liquid phase (Raynaud et al. 2012). Meanwhile, with losing protection, the microbes' cells are disrupted because of significant changes in $\mathrm{pH}$ value. Consequently, the microbes release substances and embedded water. These conditions are the primary causes of the EPS increasing in supernatants. The EPS content was higher under alkali pretreatment than under acidic pretreatment, indicating that alkali pretreatment is more effective than acidic pretreatment in terms of disintegrating sludge flocs and microbial cells.
Fig. 5 Variations of zeta potential conditioned by DDBAC and pretreatment with acid/alkali. a DDBAC-conditioned sludge alone (0 to $150 \mathrm{mg} / \mathrm{g}$ ), b DDBAC-conditioned sludge with acid-alkali pretreatment $(\mathrm{pH}$ range 1.30 to 12.86 , DDBAC dosage $75 \mathrm{mg} / \mathrm{g}$ ) a

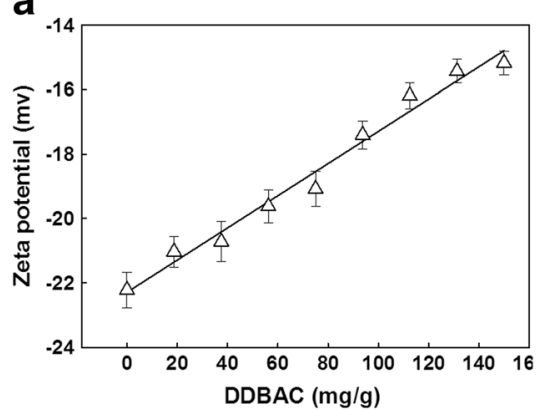

b

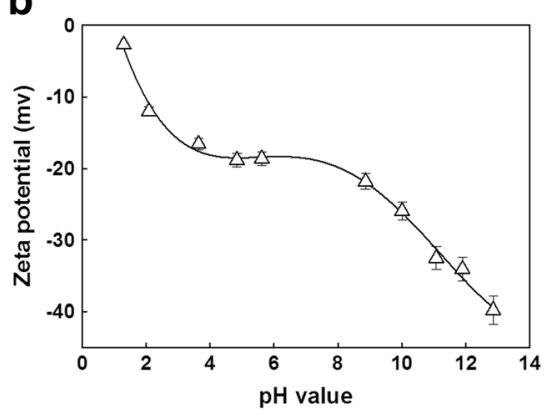


Fig. 6 Variations of rheological property conditioned by DDBAC and pretreatment with acid/alkali, the insert figures both present the point that in the shear rate of 10 1/s. a DDBAC-conditioned sludge alone (0 to $150 \mathrm{mg} / \mathrm{g}$ ). b DDBAC-conditioned sludge with acid-alkali pretreatment $(\mathrm{pH}$ range 1.30 to 12.86 , DDBAC dosage $75 \mathrm{mg} / \mathrm{g}$ )

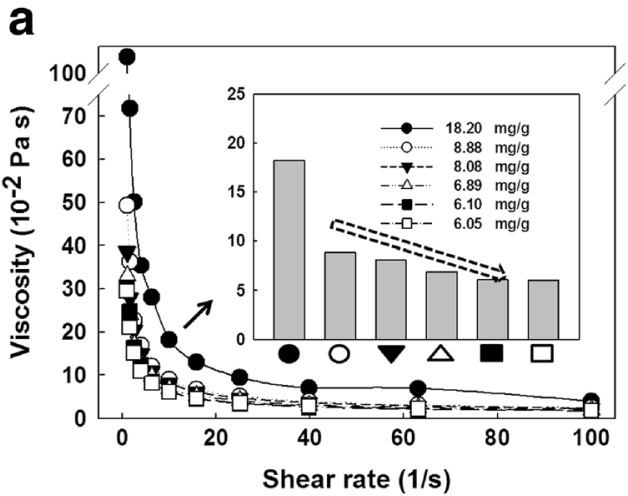

EPS had weak correlations with $W_{\mathrm{C}}$ in acidic condition, which was because weak acid and strong acid had different effects on EPS and sludge flocs. When the sludge was under weak acid, $W_{\mathrm{C}}$ in conditioning sludge was lower than that sludge conditioned by the DDBAC alone (Fig. 1b). This may be attributed to the release of bound water from the sludge flocs and microbial cells under acidic conditions. EPS has a high affinity with water and is thus highly hydrated. When under strong acidic condition, EPS in the sludge could be denatured, and its hydratability reinforced and resulting in increment in bound water content. What's more, the increasing of EPS content in supernatant also improved the electronegativity of sludge, resulting in a stronger electrostatic repulsion among broken sludge flocs and a decreased in sludge filterability. Thus, when acidity increased sharply, EPS increased and leads to correspondingly increasing of $W_{\mathrm{C}}$ and SRF (Fig. 1b).

Bound water is embedded in sludge flocs by intermolecular forces (Vesilind and Hsu 1997). It cannot be dewatered by mechanical means and be recognized as the upper limit of mechanical dewatering. Thus, bound water plays a key role in enhancing of sludge dewaterability. Colin and Gazbar (1995) found that bound water can be used to measure the extent of difficulty of mechanical dewatering. That is, greater bound water content in the sludge corresponds to more difficult mechanical removal.

This finding indicated that the decrease of $W \mathrm{c}$ was attributed to the bound water releasing under DDBAC conditioning. However, still, $40 \%$ of the bound water remained unreleased. A reasonable explanation might be that the water was bounded by stronger chemical bonds in the sludge flocs and thus could not be released.

This observation indicated that proper $\mathrm{pH}$ conditions synergistically work with surfactant, resulting in a release of more bound water. However, under strong acidic and alkaline conditions, the binding capabilities of EPS became reinforced and combined more water, and $W_{\mathrm{B}}$ increased. This finding may attribute to sludge flocs that were disintegrated into smaller ones under alkaline conditions, and a large amount of EPS was released into the solution. These results led to the enhancement of the electronegativity in sludge flocs and strengthened the repulsive forces between sludge flocs. Thus, it was difficult to filtrate for sludge because of the deterioration of filterability. These results indicated that the joint effect of the decrease of bound water and the improvement of filterability cause the decrement of $W_{\mathrm{C}}$.

The zeta potential is proportional to the electric charges of charged particles. By measuring the value of the zeta potential, the quantity of electric charges on the sludge flocs can be found out. The value of the zeta potential determines the repelling forces among sludge particles that affect sludge dewaterability (Liu and Fang 2003). Electrostatic repulsive forces among particles hinder the aggregation and sedimentation of sludge flocs and thus make the sludge more stable.

This finding could attribute to the different kinds of charges carried by sludge flocs and DDBAC, respectively. Since EPS carried negative charges and DDBAC was a cationic surfactant, charge neutralization occurred between DDBAC and EPS. As a result, the electrostatic repulsive forces among the sludge were weakened and sludge dewaterability was enhanced.

Proteins of EPS were denatured under strong acidic conditions, resulting in a decrease of the negative electric charge group (i.e., hydroxyl and amino) contents and a reduction of the EPS surface negative electric charge intensity. Under alkali condition, the extremely high EPS content caused electronegativity increasing dramatically, and yield enhanced repulsive force among sludge flocs.

Figure 6 showed the changes in rheological properties under DDBAC conditioning with acid/alkali pretreatment. The apparent viscosity of sludge decreased with an increase in shear rate, that is, the sludge became more fluid. Basing on this property, sludge was determined as pseudoplastic in nonNewtonian fluid (Liu and Fang 2003; Rosenberger and Kraume 2002). EPS enabled this bio-media to adhere to one another and form a net-like zoogloea floc structure (Rosenberger and Kraume 2002; Mowla et al. 2013; Wilén et al. 2003). Under application of DDBAC, EPS on sludge flocs began to dissolve and disintegrate where the net-like structure was gradually disrupted, surface tension and flow resistance weakened, and the apparent viscosity decreased. 
This finding was probably because plentiful nondissolvable EPS released and sludge flocs disintegrated into small ones during acid/alkali pretreatment. EPS combined those small sludge flocs and formed a new stable net structure, which enhanced the stabilization of sludge.

In conclusion, the effect of DDBAC on sludge dewaterability depended on the amount of DDBAC and the $\mathrm{pH}$ value. Compared with the independent application of DDBAC, the joint pretreatment of weak acid and surfactant could enhance the sludge dewaterablity. However, under DDBAC conditioning with strong acid/alkaline pretreatment, sludge dewatering performance decreased. $W_{\mathrm{C}}$ and SRF results indicated that the optimal condition for sludge treatment is a $\mathrm{pH}$ value of 4.84 and a surfactant of $75 \mathrm{mg} / \mathrm{g}$.

EPS contents in sludge supernatant, zeta potential, and apparent viscosity were important factors that affect sludge dewaterability. Increasing in EPS content boosted electronegativity and apparent viscosity, which had a negative effect on sludge dewaterability. The application of DDBAC and acid/alkaline pretreatment helped release bound water and increased the content of removable water. However, $W_{\mathrm{C}}$ was simultaneously determined by of $W_{\mathrm{B}}$ and filterability (SRF). Under strong alkali conditions, the filterability of sludge deteriorated substantially, which led $W_{\mathrm{C}}$ to increase, whereas $W_{\mathrm{B}}$ decreased.

Acknowledgments This work was supported by the National Natural Science Foundation of China (No. 51104009), Beijing Nova Program (No. Z111106054511043), Beijing Outstanding Talent Nurture and Funding Scheme (No. 2012D009006000003), and the Fundamental Research Funds for the Central Universities (No. FRF-TP-12-011B).

\section{References}

Bolto B, Gregory J (2007) Organic polyelectrolytes in water treatment. Water Res 41:2301-2324

Burton K (1968) Determination of DNA concentration with diphenylamine. Methods Enzymol 12:163-166

Chen Y, Gu G (2004) Influence of pretreating activated sludge with acid and surfactant prior to conventional conditioning on filtration dewatering. Chem Eng J 99:137-143

Chen Y, Yang H, Gu G (2001) Effect of acid and surfactant treatment on activated sludge dewatering and settling. Water Res 35:2615-2620

Colin F, Gazbar S (1995) Distribution of water in sludges in relation to their mechanical dewatering. Water Res 29:2000-2005

Feng X, Deng J, Lei H, Bai T, Fan Q, Li Z (2009) Dewaterability of waste activated sludge with ultrasound conditioning. Bioresour Technol 100:1074-1081

Houghton JI, Quarmby J, Stephenson T (2001) Municipal wastewater sludge dewaterability and the presence of microbial extracellular polymer. Water Sci Technol 44:373-379

Hua XF, Wang J, Zj W, Zhang HX, Li HP, Xing XH, Liu Z (2010a) A salt tolerant Enterobacter cloacae mutant for bioaugmentation of petroleum- and salt-contaminated soil. Biochem Eng J 49:201-206

Hua XF, Wu ZJ, Zhang HX, Lu DN, Wang M, Liu YM, Liu Z (2010b) Degradation of hexadecane by Enterobacter cloacae strain TU that secretes an exopolysaccharide as a bioemulsifier. Chemosphere 80: 951-956

Huang C, Fu G (2000) Effect of surfactant on alum sludge conditioning and dewaterability. Water Sci Technol 41:17-22

Jiang S, Chen Y, Zhou Q, Gu G (2007) Biological short-chain fatty acids (SCFAs) production from waste-activated sludge affected by surfactant. Water Res 41:3112-3120

Jin B, Wilén B, Lant P (2004) Impacts of morphological, physical and chemical properties of sludge flocs on dewaterability of activated sludge. Chem Eng J 98:115-126

Liu Y, Fang H (2003) Influences of extracellular polymeric substances (EPS) on flocculation, settling, and dewatering of activated sludge. Crit Rev Environ Sci Technol 33:237-273

Liu H, Yang J, Zhu N, Zhang H, Li Y, He S, Yang C, Yao H (2013) A comprehensive insight into the combined effects of Fenton's reagent and skeleton builders on sludge deep dewatering performance. $\mathrm{J}$ Hazard Mater 258-259:144-150

Lo IM, Lai KC, Chen GH (2001) Salinity effect on mechanical dewatering of sludge with and without chemical conditioning. Environ Sci Technol 35:4691-4696

Lowry OH, Rosebrough NJ, Farr AL, Randall RJ (1951) Protein measurement with the Folin phenol reagent. J Boil Chem 193:265-275

Luo K, Yang Q, Yu J, Li X, Yang G, Xie B, Yang F, Zheng W, Zeng G (2011) Combined effect of sodium dodecyl sulfate and enzyme on waste activated sludge hydrolysis and acidification. Bioresour Technol 102:7103-7110

Ma W, Zhao YQ, Kearney P (2007) A study of dual polymer conditioning of aluminum-based drinking water treatment residual. J Environ Sci Health A 42:961-968

Mowla D, Tran HN, Allen DG (2013) A review of the properties of biosludge and its relevance to enhanced dewatering processes. Biomass Bioenergy 58:365-378

Neyens E, Baeyens J (2003) A review of classic Fenton's peroxidation as an advanced oxidation technique. J Hazard Mater 98:33-50

Neyens E, Baeyens J, Dewil R (2004) Advanced sludge treatment affects extracellular polymeric substances to improve activated sludge dewatering. J Hazard Mater 106:83-92

Novak JT, Sadler ME, Murthy SN (2003) Mechanisms of floc destruction during anaerobic and aerobic digestion and the effect on conditioning and dewatering of biosolids. Water Res 37:3136-3144

Raynaud M, Vaxelaire J, Olivier J, Dieude-Fauvel E, Baudez J (2012) Compression dewatering of municipal activated sludge: effects of salt and $\mathrm{pH}$. Water Res 46:4448-4456

Riesz P, Berdahl D, Christman CL (1985) Free radical generation by ultrasound in aqueous and nonaqueous solutions. Environ Health Perspect 64:233

Rosenberger S, Kraume M (2002) Filterability of activated sludge in membrane bioreactors. Desalination 146:373-379

Rosenberger S, Evenblij H, Te Poele S, Wintgens T, Laabs C (2005) The importance of liquid phase analyses to understand fouling in membrane assisted activated sludge processes-six case studies of different European research groups. J Membr Sci 263:113-126

Tokumura M, Sekine M, Yoshinari M, Znad HT, Kawase Y (2007) Photo-Fenton process for excess sludge disintegration. Process Biochem 42:627-633

Vaxelaire J, Cézac P (2004) Moisture distribution in activated sludges: a review. Water Res 38:2215-2230

Vesilind PA, Hsu C (1997) Limits of sludge dewaterability. Water Sci Technol 36:87-91

Wang F, Ji M, Lu S (2006) Influence of ultrasonic disintegration on the dewaterability of waste activated sludge. Environ Prog Sustain 25: 257-260

Wilén B, Jin B, Lant P (2003) Impacts of structural characteristics on activated sludge floc stability. Water Res 37:36323645 
Yu G, He P, Shao L, He P (2008) Stratification structure of sludge flocs with implications to dewaterability. Environ Sci Technol 42:7944 7949

Yuan H, Cheng X, Chen S, Zhu N, Zhou Z (2011a) New sludge pretreatment method to improve dewaterability of waste activated sludge. Bioresour Technol 102:5659-5664

Yuan H, Zhu N, Song F (2011b) Dewaterability characteristics of sludge conditioned with surfactants pretreatment by electrolysis. Bioresour Technol 102:2308-2315
Zhang D, Chen Y, Zhao Y, Zhu X (2010) New sludge pretreatment method to improve methane production in waste activated sludge digestion. Environ Sci Technol 44:4802-4808

Zhang XM, Yue XP, Liu ZQ, Li QQ, Hua XF (2015) Impacts of sludge retention time on sludge characteristics and membrane fouling in a submerged anaerobic-oxic membrane bioreactor. Appl Microbiol Biotechnol. doi:10.1007/s00253-015-6383-x

Zhao YQ, Bache DH (2001) Conditioning of alum sludge with polymer and gypsum. Colloids Surf A 194:213-220 